\title{
Efficacy of a seawater solution enriched with copper, hyaluronic acid and eucalyptus against nasal pathogens*
}

\section{Song Huang ${ }^{1}$, Samuel Constant ${ }^{1}$, Barbara De Servi' ${ }^{2}$, Marisa Meloni², Josip Culig ${ }^{3}$, Amina Saaid ${ }^{4}$}

Rhinology Online, Vol 2: 119 - 124, 2019

http://doi.org/10.4193/RHINOL/19.019

*Received for publication:

May 10, 2019

Accepted: December 3, 2019

Published: December 14, 2019

\begin{abstract}
Background: Common cold is the most common disease which mainly affects the upper respiratory system. It is caused by viral or, in a small percentage, by bacterial infections. Current therapy options focus on symptomatic relief of the disease such as nasal saline irrigation, an easy-to-apply, comfortable, non-toxic method. In this study, a novel hypertonic seawater solution enriched with hyaluronic acids, eucalyptus oil, copper and manganese salts, Stérimar Stop \& Protect Cold and Flu (SSPCF), has been investigated with respect to efficacy against viral and microbial infections.
\end{abstract}

Methodology: An in vitro 3D reconstituted human nasal epithelium tissue model, MucilAir ${ }^{\mathrm{TM}}$, has been used in this study. Pretreatment and post-treatment anti-viral effects of SSPCF was measured through HRV-A16 viral load assays in order to evaluate the preventive and therapeutic efficacy of SSPCF, respectively. Anti-bacterial effects of SSPCF was assessed via Staphylococcus (S.) aureus growth inhibition and fluorescence bead-based phagocytosis assays.

Results: One-hour SSPCF treatment pre- or post-viral infection inhibited the viral replication up to 99.78 and $59.91 \%$, respectively. S. aureus growth was completely eliminated (100\%) in SSPCF treated tissues after 1 hour of treatment. Phagocytosis rate was 3.28 folds higher in SSPCF treated tissue as compared to saline treated controls.

Conclusions: Under the conditions of this in vitro study, SSPCF appears effective against some species of rhinoviruses (as in common cold) and S. aureus in vitro.

Key words: hypertonic seawater, nasal irrigation, Staphylococcus aureus, common cold, rhinovirus, HRV-A16

\section{Introduction}

Common cold (viral acute rhinosinusitis) is an upper respiratory tract infection which primarily affects the nasal respiratory mucosa and mainly causes nasal blockage/obstruction/congestion for a duration of less than 10 days ${ }^{(1)}$. Children and adults are estimated to suffer from up to 5 and 3 colds per year, respectively ${ }^{(2)}$, which also causes time-off from school or work, translating to an economic and social burden ${ }^{(3)}$. Rhinovirus infections are the main cause of common cold cases and lead to epithelial barrier dysfunction without causing cell death and enhance the invasion of bacteria which may cause bacterial superinfections ${ }^{4-4}$ 6). When common cold symptoms worsen after 5 days or persist for more than ten days up to 12 weeks, the disease is called post-viral acute rhinosinusitis. A small subgroup of the postviral rhinosinusitis (estimated around $0.5-2.0 \%)^{(7)}$ is caused by bacteria (mainly S. pneumoniae, H. influenzae, M. catarrhalis and S. aureus) to develop acute bacterial rhinosinusitis ${ }^{(1)}$.

Treatment options for common cold concentrate around symptomatic relief ${ }^{(8)}$, among which, nasal irrigation (NI) with 
saline solution is recommended as a safe, easy-to-use, comfortable and not-expensive method ${ }^{(9)}$. In addition, NI has been shown to, at least partially, remove viruses and inflammatory mediators, and inhibit viral replication in the nasal cavities in upper respiratory tract infections ${ }^{(10)}$. Saline $\mathrm{NI}$ applications also have been shown to decrease sinus medicine use in 35\% of patients ${ }^{(11)}$. Ragab et al. showed that there are no differences in nasal and total symptom scores of children with common cold who received saline $\mathrm{NI}$ combined with amoxicillin or placebo treatment. In the placebo group, children presented less adverse effects, suggesting that the saline $\mathrm{Nl}$ alone (no antibiotic) is not only sufficient but also safer ${ }^{(12)}$. Thus, improving the NI formulations may improve the symptomatic relief outcomes with a better safety profile and contribute to the decrease in the irrational use of medicinal products.

Hypertonic solutions are frequently used for $\mathrm{NI}$ and, due to their high salt concentration, were claimed to reduce oedema by draining water from surrounding tissues through diffusion of osmolar gradients ${ }^{(13)}$, and have been shown to be effective in the elimination of nasal congestion in chronic rhinosinusitis ${ }^{(14)}$. In addition, in vitro studies have shown that hypertonic saline solutions are safe to use on nasal tissues as they do not compromise nasal epithelial integrity ${ }^{(15)}$.

In this study, anti-viral and anti-bacterial properties of a hypertonic seawater formulation $(2.3 \% \mathrm{NaCl})$ enriched with hyaluronic acids, eucalyptus oil, copper and manganese salts, Stérimar Stop \& Protect Cold and Flu (SSPCF), were tested in vitro. Additionally, the effect of the formulation on phagocytosis was evaluated.

\section{Materials and Methods}

Biological model (test system) used for the in vitro studies The in vitro assays were performed in a 3D reconstituted human nasal epithelium model, MucilAir ${ }^{\mathrm{TM}}$ (Epithelix Sàrl, Geneva, Switzerland) for its great potential as a model to test respiratory sensitizers ${ }^{(16,17)}$. For maintenance, inserts were incubated in $500 \mu$ l of MucilAir ${ }^{\mathrm{TM}}$ culture medium in a $\mathrm{CO}_{2}$ incubator $\left(37^{\circ} \mathrm{C}, 5 \%\right.$ $\mathrm{CO}_{2}, 100 \%$ humidity, Heracell).

\section{Viral load assays}

Replication of HRV-A16 has been previously shown to be successful in the MucilAir ${ }^{\mathrm{TM}}$ model in which the viral RNA load reaches a maximum in $24-48$ hours after infection ${ }^{(18)}$. In order to evaluate the effect of SSPCF on viral load, both pre- and posttreatment approaches were followed.

\section{Effect of treatment prior to HRV-A16 infection}

HRV-A16 virus stocks were prepared in HeLa Ohio and Vero cells as previously described ${ }^{(19)}$. Prior to viral inoculation, tissues were treated 1 hour with saline (0.9\%) (in triplicate) or SSPCF
( $n=3$ ) or $5 m$ M Rupintrivir ( $n=2$, Santa Cruz Biotechnology Inc., Dallas, Texas, United States), a potent and irreversible inhibitor of human rhinovirus $3 \mathrm{C}$ protease ${ }^{(20)}$. At 0 h, tissues were apically inoculated with $100 \mu \mathrm{l} \mathrm{HRV-A16}\left(2.8 \times 10^{6} \mathrm{RNA}\right.$ copies $\left./ \mathrm{ml}\right)$. After 3.5 hours of incubation at $34^{\circ} \mathrm{C}$, supernatants were aspirated, and tissues were rinsed. $200 \mu \mathrm{l}$ of MucilAir ${ }^{\mathrm{TM}}$ culture medium was added for 20 minutes and the virus were harvested. The epithelia were further cultured at the air-liquid interface. At 24h, viral load was collected the same way. The viral load was quantified with Entero/Ge/08 one-step real-time PCR as previously described ${ }^{(19,21)}$.

\section{Effect of treatment after HRV-A16 infection}

At 0 , tissues were inoculated with $100 \mu$ l of HRV-A16 viral suspension $\left(2.8 \times 10^{4}\right.$ RNA copies $\left./ \mathrm{ml}\right)$. Virus were rinsed out by $200 \mu \mathrm{l}$ of MucilAir ${ }^{\mathrm{TM}}$ culture media for 20 minutes. Tissues were treated with SSPCF ( $n=3)$ and 5000nM Rupintrivir $(n=3)$ or saline $(0.9 \%)$ $(n=3)$ for $24 h$, and further incubated for 24 hours. Supernatants were lysed, and viral load was quantified. RNA was extracted with the QIAamp ${ }^{\oplus}$ (Qiagen, Hilden, Germany) Viral RNA Mini Kit. The extracted RNA was then quantified with the QuantiTect RTPCR kit (Qiagen, Hilden, Germany) by TaqMan ABI 7000 instrument (Applied Biosystems, Waltham, MA, USA).

\section{Bacterial assay}

S. aureus (ATCC 6538) was thawed out and subcultured in TCS agar plates and then grown in suspension at $30-35^{\circ} \mathrm{C}$ up to $3.2 \times 10^{6} \mathrm{CFUs}$ (calculated by $\mathrm{OD}_{620}$ ). SSPCF was added to the suspension to a final concentration of $1 \%$, to ensure minimal changes in growth characteristics. Incubations were then performed under rotary agitation ( 180 rotations $/ \mathrm{min}$ ) at $35^{\circ} \mathrm{C}$. Monitoring was carried out at $0,1,3$ and $24 \mathrm{~h}$ of incubation by measuring the bacterial density (calculated as CFU/ml). As negative control, untreated samples (growth medium) was used.

\section{Phagocytosis assay}

To evaluate whether SSPCF can induce phagocytic activity, tissues were treated for 1 hour with control (saline solution) or SSPCF, containing-FITC coupled latex beads. A volume of $100 \mu \mathrm{l}$ of rabbit lgG-FITC conjugated-coated latex beads (1:10 saline dilution) (Phagocytosis assay kit, Cayman Chemical Company, Ann Arbor, MI, USA) were added to tissues and incubated in $30 \mu \mathrm{l}$ of saline or SSPCF in 24-well plates. Tissues were incubated for 1 hour for $37^{\circ} \mathrm{C} .50 \mu$ l of Trypan Blue solution were added and plates were incubated at RT for 2 min to quench FITC fluorescence of non-internalized beads. Excess Trypan Blue was aspirated, and fluorescence intensity of the cells was measured $(485 \mathrm{~nm} / 535 \mathrm{~nm})$. Cells were also analysed in an inverted fluorescent microscope (Leica DM IL LED FLUO, Wetzlar, Germany) equipped with filters $(485 \mathrm{~nm} / 535 \mathrm{~nm})$ after supernatant aspiration. 
A

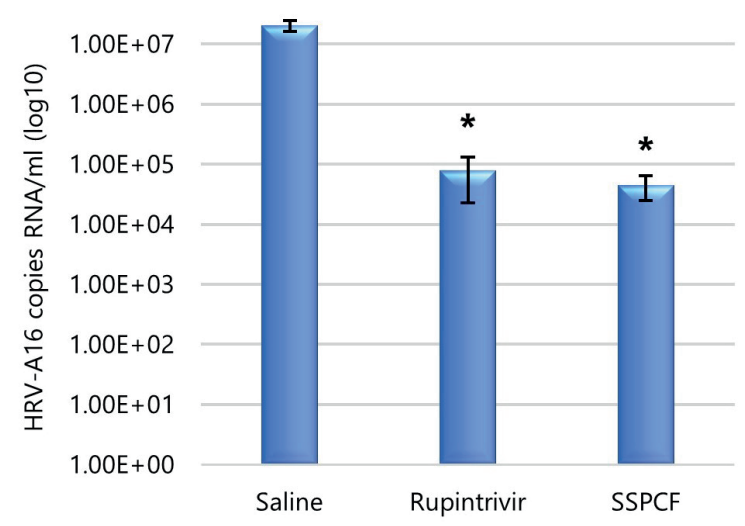

B

Treatment after infection

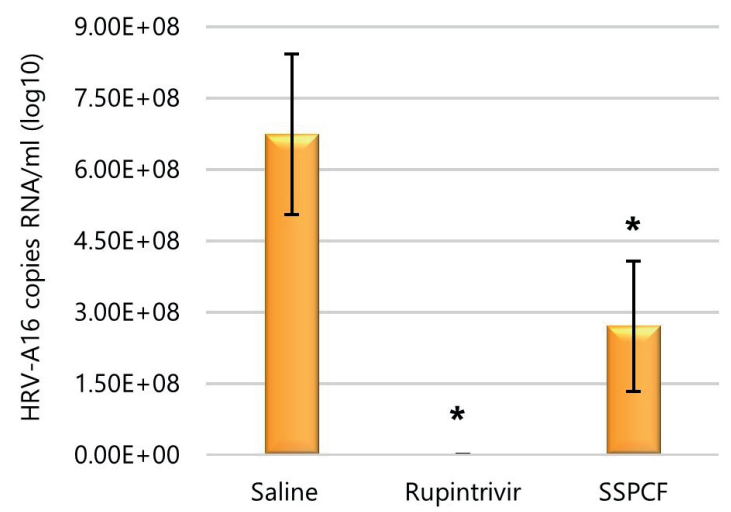

Figure 1. Effect of SSPCF on viral load (A) before HRV-A16 infection and (B) after HRV-A16 infection. ${ }^{*} \mathrm{p} \leq 0.05$ compared to saline control.

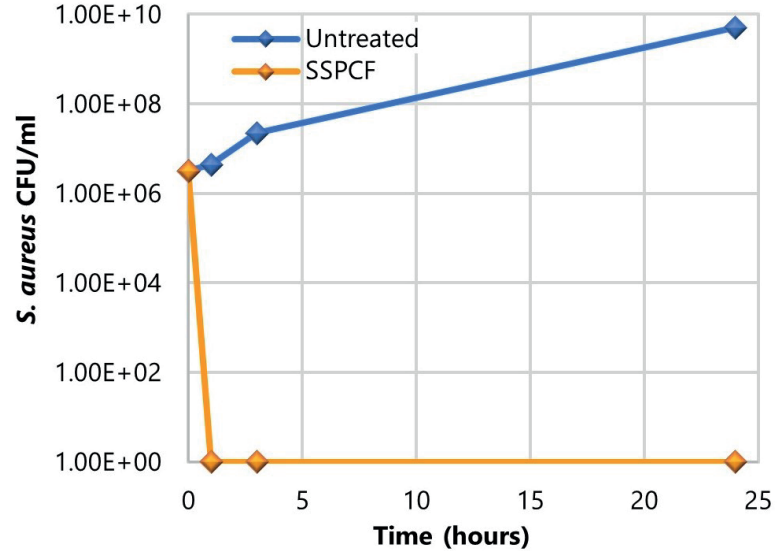

Figure 2. Efficacy of SSPCF against S. aureus growth. Chart shows the bacterial growth in suspensions incubated with or without (growth control) $1 \%$ of SSPCF at $0 \mathrm{~h}$ (incubation start point), $1 \mathrm{~h}, 3 \mathrm{~h}$ and $24 \mathrm{~h}$ post treatment.

\section{Results}

\section{Effect on viral replication}

Results of 1-hour SSPCF pre-treatment before HRV-A16 infection showed that viral replication was almost completely inhibited in this sample as compared to saline-treated control (99.78\% inhibition, $2.05 \times 10^{7}$ vs $4.50 \times 10^{4}$, respectively (Figure $1 \mathrm{~A}$ ). The effect of SSPCF was similar to the effect of rupintrivir.

Results of the post-infection treatment ( 24 hours after infection) showed that 24 hours of treatment (48 hours after infection) decreased the viral load compared to saline-treated control, reaching up to $60 \%$ inhibition $\left(6.73 \times 10^{8}\right.$ vs. $2.70 \times 10^{8}$ copies RNA/ $\mathrm{ml}$ ) (Figure 1B).

\section{Effect on bacterial growth}

The efficacy of SSPCF against S. aureus was tested by monitoring of bacterial growth at 1, 3 and 24 hours after treatment. As shown in Figure 2, treatment with SSPCF has an anti-bacterial effect compared to untreated control (growth medium). Starting from as early as one hour after treatment the $S$. aureus colony forming unit counts decreased from over $1.0 \times 10^{6}$ to 0 and is maintained throughout the course of the experiment (24h).

\section{Effect on the phagocytic activity of nasal epithelial cells} Figure 3A presents fluorescent micrographs of cells derived from SSPCF or saline pre-treated tissues incubated with fluorescent beads. Tissues treated with SSPCF engulfed more beads indicating an increased phagocytotic activity compared to saline control. The quantification of fluorescence intensity revealed that the increase was more than 3 -fold (Figure 3B, $\mathrm{p}<0.001$ ).

\section{Discussion}

The present study aimed to test the efficacy of a hypertonic seawater solution enriched with hyaluronic acids, eucalyptus oil as well as copper and manganese salts against pathogens such as human rhinovirus which are known to cause common cold $(4,5)$ and $S$. aureus which is an important pathogen in respiratory infections ${ }^{(22)}$, in an in vitro model of reconstituted human nasal epithelium. Manganese has been shown to inhibit the anaphylactic histamine release ${ }^{(23)}$ and reduces inflammatory response (24). Hyaluronic acid increases tissue hydration and shortens healing time ${ }^{(25,26)}$.

The model used in this study, MucilAir ${ }^{\mathrm{TM}}$ is composed of basal cells, ciliated cells and mucus cells in a proportion similar to what one observes in vivo ${ }^{(27)}$. Moreover, MucilAir ${ }^{\mathrm{TM}}$ is functionally differentiated, conserves tissue integrity $\left(\right.$ TEER $\left.>200 \mathrm{~W} . \mathrm{cm}^{2}\right)$ and also secretes mucus. The activity of the main epithelial ionic channels, such as CFTR, EnaC, Na/K ATPase, is preserved and the epithelia is shown to respond in a regulated and vectorial manner to the pro-inflammatory stimulus, TNF- $\alpha{ }^{(27)}$. A large panel of 
A

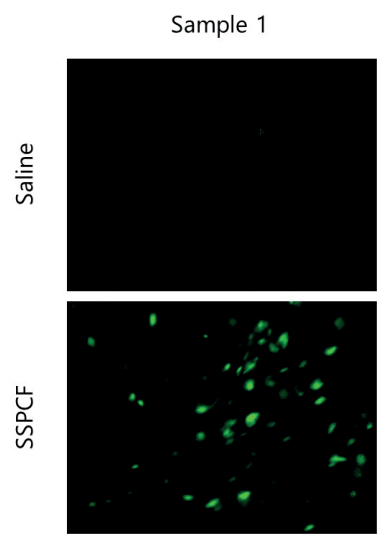

Sample 2

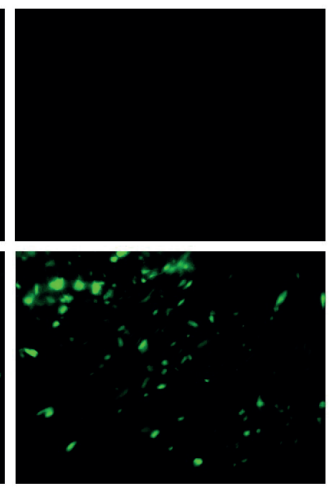

B

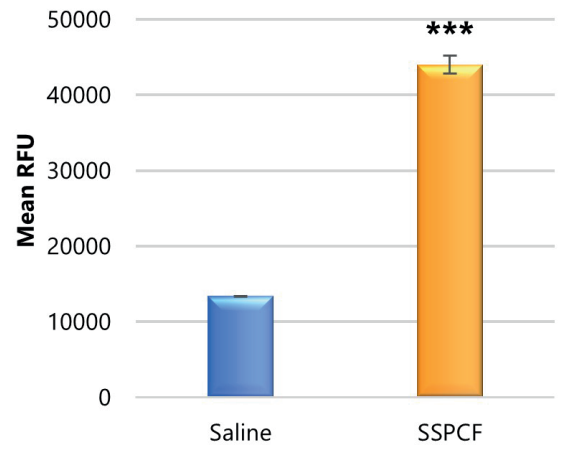

Figure 3. Phagocytic activity after SSPCF pre-treatment. A, Representative fluorescent images of cells derived from MucilAir ${ }^{\mathrm{TM}}$ tissues with internalized fluorescent beads after 1-hour treatment. B, Quantification of data in (A). ${ }^{* * *} \mathrm{p}<0.001$ compared to saline control.

cytokines, chemokines and metalloproteinases has been detected in MucilAir ${ }^{\text {TM }}$ tissues (e.g. IL-8, IL-6, GM-CSF, MMP-9, GRO-a). Most importantly, MucilAir ${ }^{\mathrm{TM}}$ replicates the main function of the airway epithelial cells, the mucociliary clearance driven by synchronized cilia-beating, and has been successfully used for acute, long-term and chronic in vitro studies ${ }^{(16,17,28,29)}$. Given that MucilAir $^{\mathrm{TM}}$ is functionally robust and successfully mimics human nasal epithelium, it is important to conduct a clinical trial with SSPCF in order to demonstrate the safety and efficacy of it in in vivo settings.

At the performance level, treatment with SSPCF prior to HRVA16 infection reduced viral load compared to saline-treated cells (almost 100\%), as measured by viral RNA copy numbers, indicating the inhibition of rhinovirus replication. The reduction was similar to the one caused by treatment with rupintrivir, a well-known viral protease inhibitor ${ }^{(20)} .60 \%$ viral replication inhibition was also observed when treatment was performed after viral infection. Therefore, SSPCF has a prophylactic effect against HRV-A16 and is also effective when used post-infection ( 100\% and $60 \%$ inhibition, respectively).

In addition, efficacy of SSPCF in control of bacterial growth was also assessed. The results in Figure 1 show that, as early as 1 hour after treatment, SSPCF exerted anti-bacterial effect on S. aureus growth (complete inhibition), compared to untreated control cultures.

Respiratory epithelial cells orchestrate the immune defense response against incoming toxins and pathogens. Pathogen recognition pathways in epithelial cells can stimulate phagocytosis ${ }^{(30)}$. An increase in phagocytic activity was also observed upon treatment with SSPCF compared to treatment with saline solution. The performed assay employed IgG-FITC conjugated latex beads. It would be interesting to investigate whether there is an increase in phagocytosis of HRV-A16 or S. aureus via live cell imaging to confirm that the increase in phagocytic activity shown with fluorescent beads is contributing to an antimicrobial effect. Others have previously shown that primary nasal epithelial cells cultured in vitro in an air-liquid interface similar to the MucilAir ${ }^{\mathrm{TM}}$ model, are able to phagocyte other pathogens such as Aspergillus fumigatus (31).

Upon colonizing the nose, S. aureus competes with the bacteria of the nasal microflora and has been shown to form a biofilm enabling other bacteria species to grow ${ }^{(32)}$. Biofilms provide bacteria with a protective environment against host defense which may lead to chronic diseases such as chronic rhinosinusitis ${ }^{(33)}$. In this regard, topical irrigation treatments, including nasal saline irrigation, have been shown to be effective in the elimination of biofilms both in animal and human chronic rhinosinusitis models as reviewed recently ${ }^{(34)}$. Therefore, the prevention of bacterial growth demonstrated in this in vitro study may be due to the partial or complete elimination of biofilm, or the prevention of its formation.

\section{Conclusions}

Overall, results of the present study support that in vitro, SSPCF is able to inhibit HRV-A16 replication and S. aureus growth, and SSPCF is effective in protecting the nasal epithelial tissues from viral and bacterial pathogens. In vitro tests presented in this study suggest that SSPCF has (i) an inhibitory effect on viral replication when applied pre- or post-infection by HRV A16, (ii) anti-bacterial effect on S. aureus; and (iii) phagocytosis-enhancing effect that could be useful against viruses and bacteria involved in common cold. Safety and efficacy evaluation of SSPCF in the clinical settings is needed to prove the beneficial effects of the formulation at the clinical level. 


\section{Acknowledgement}

Authors would like to thank Dr. Philippe Contencin and Dr. Annahita Ghassemi for their valuable contribution to the elaboration and revision of the manuscript.

\section{Authorship contribution}

SC, MM and AS established the study conception and design. $\mathrm{SH}$ and BDS developed the experimental methodology. SH and BDS acquired, analysed and interpreted data. JC and AS wrote, reviewed and revised the manuscript. SC, MM and AS supervised the study.

\section{Conflict of interest}

AS works as EU Technology \& Innovation Manager at Church \&
Dwight, Co., Inc. SH, SC, BDS, MM and JC declare no conflict of interest in this work.

\section{Ethics approval and consent to participate}

Not applicable.

\section{Consent for publication}

Not applicable.

\author{
Availability of data and materials \\ Not applicable.
}

\section{Funding}

This study has been sponsored by Church \& Dwight, Co., Inc.

\section{References}

1. Fokkens WJ, Lund VJ, Mullol J, Bachert C, Alobid I, Baroody F, et al. EPOS 2012 European position paper on rhinosinusitis and nasal polyps 2012. A summary for otorhinolaryngologists. Rhinology. 2012;50(1):1-12

2. Arroll B. Common cold. BMJ Clin Evid. 2011;2011. pii:1510

3. Leder K, Sinclair MI, Mitakakis TZ, Hellard ME, Forbes A. A community-based study of respiratory episodes in Melbourne, Australia. Aust N Z J Public Health. 2003;27(4):399-404

4. Makela MJ, Puhakka T, Ruuskanen O, Leinonen M, Saikku P, Kimpimaki M, et al. Viruses and bacteria in the etiology of the common cold. J Clin Microbiol. 1998;36(2):539-42.

5. Allan GM, Arroll B. Prevention and treatment of the common cold: making sense of the evidence. CMAJ. 2014;186(3):190-9.

6. Sajjan U, Wang Q, Zhao Y, Gruenert DC Hershenson MB. Rhinovirus disrupts the barrier function of polarized airway epithelial cells. Am J Respir Crit Care Med. 2008;178(12):1271-81

7. Anselmo-Lima WT, Sakano E, Tamashiro E, Nunes AA, Fernandes AM, Pereira EA, et al. Rhinosinusitis: evidence and experience. A summary. Braz J Otorhinolaryngol. 2015;81(1):8-18.

8. Fashner J, Ericson K, Werner S. Treatment of the common cold in children and adults. Am Fam Physician. 2012;86(2):153-9.

9. King D, Mitchell B, Williams CP, Spurling GK Saline nasal irrigation for acute upper respiratory tract infections. Cochrane Database Syst Rev. 2015;(4):CD006821

10. Ao H, Wang $Q$, Jiang $B$, He P. Efficacy and mechanism of nasal irrigation with a hand pump against influenza and non-Influenza viral upper respiratory tract infection. Journal of Infectious Diseases and Immunity. 2011;3(6):96-105

11. Heatley DG, McConnell KE, Kille TL, Leverson GE. Nasal irrigation for the alleviation of sinonasal symptoms. Otolaryngol Head Neck Surg. 2001;125(1):44-8

12. Ragab A, Farahat T, Al-Hendawy G, Samaka R, Ragab S, El-Ghobashy A. Nasal saline irrigation with or without systemic antibiotics in treatment of children with acute rhinosinusitis. Int J Pediatr Otorhinolaryngol. 2015;79(12):2178-86.

13. Talbot AR, Herr TM, Parsons DS. Mucociliary clearance and buffered hypertonic saline solution. Laryngoscope. 1997;107:500-3

14. Culig J, Leppee M, Vceva A, Djanic D. Efficiency of hypertonic and isotonic seawater solutions in chronic rhinosinusitis. Med Glas (Zenica). 2010;7(2):116-23.

15. Ramezanpour M, Rayan A, Smith JL, Vreugde $\mathrm{S}$. The effect of topical treatments for CRS on the sinonasal epithelial barrier. Rhinology. 2017 Jun;55(2):161-9.

16. Essaidi-Laziosi M, Brito F, Benaoudia S, Royston L, Cagno V, Fernandes-Rocha M et al. Propagation of respiratory viruses in human airway epithelia reveals persistent virus-specific signatures. J Allergy Clin Immunol. 2018;141(6):2074-84.

17. Balogh Sivars K, Sivars U, Hornberg $E_{\text {, }}$ Zhang $\mathrm{H}$, Branden L, Bonfante R, et al. A 3D Human Airway Model Enables Prediction of Respiratory Toxicity of Inhaled Drugs In Vitro. Toxicol Sci. 2018;162(1):301-8.

18. Tapparel C, Sobo K, Constant S, Huang S, Van Belle S, Kaiser L. Growth and characterization of different human rhinovirus $C$ types in three-dimensional human airway epithelia reconstituted in vitro. Virology. 2013;446(1-2):1-8

19. Schibler M, Gerlach D, Martinez Y, Belle SV, Turin L, Kaiser L, et al. Experimental human rhinovirus and enterovirus interspecies recombination. J Gen Virol. 2012;93(Pt 1):93101

20. Patick AK, Binford SL, Brothers MA, Jackson $\mathrm{RL}$, Ford CE, Diem MD, et al. In vitro antiviral activity of AG7088, a potent inhibitor of human rhinovirus $3 \mathrm{C}$ protease. Antimicrob Agents Chemother. 1999;43(10):2444-50

21. Tapparel C, Cordey S, Van Belle S, Turin L,
Lee WM, Regamey N, et al. New molecular detection tools adapted to emerging rhinoviruses and enteroviruses. J Clin Microbiol. 2009;47(6):1742-9.

22. Tong SY, Davis JS, Eichenberger E, Holland TL, Fowler VG, Jr. Staphylococcus aureus infections: epidemiology, pathophysiology, clinical manifestations, and management. Clin Microbiol Rev. 2015;28(3):603-61.

23. Foreman JC, Mongar JL. The action of lanthanum and manganese on anaphylactic histamine secretion. Br J Pharmacol. 1973;48(3):527-37.

24. Li C, Zhou HM. The role of manganese superoxide dismutase in inflammation defense. Enzyme Res. 2011;2011:387176.

25. Ialenti A, Di Rosa M. Hyaluronic acid modulates acute and chronic inflammation. Agents Actions. 1994;43(1-2):44-7.

26. Kapoor P, Sachdeva S. Topical hyaluronic Acid in the management of oral ulcers. Indian J Dermatol. 2011;56(3):300-2.

27. Huang S, Wiszniewski L, Constant S. The use of in vitro 3D cell models in drug development for respiratory diseases. InDrug Discovery and Development-Present and Future 2011

28. Boda B, Benaoudia S, Huang S, Bonfante R, Wiszniewski L, Tseligka ED, et al. Antiviral drug screening by assessing epithelial functions and innate immune responses in human 3D airway epithelium model. Antiviral Res. 2018;156:72-9.

29. Hoffmann W, Gradinaru J, Farcal L, CaulFuty M, Huang S, Wiszniewski L, et al. Establishment of a human 3D tissue-based assay for upper respiratory tract absorption. Appl In Vitro Toxicol. 2018;4(2):139-48.

30. Whitsett JA, Alenghat T. Respiratory epithelial cells orchestrate pulmonary innate immunity. Nat Immunol. 2015;16(1):27-35.

31. Botterel F, Gross K, Ibrahim-Granet O, Khoufache K, Escabasse V, Coste A, et al. Phagocytosis of Aspergillus fumigatus conidia by primary nasal epithelial cells in vitro. BMC Microbiol. 2008;8:97.

32. Peacock SJ, de Silva I, Lowy FD. What deter- 
mines nasal carriage of Staphylococcus aureus? Trends Microbiol. 2001;9(12):605-10

33. Archer NK, Mazaitis MJ, Costerton JW, Leid JG, Powers ME, Shirtliff ME. Staphylococcus aureus biofilms: properties, regulation, and roles in human disease. Virulence. 2011;2(5):445-59.

34. Ramakrishnan Y, Shields RC, Elbadawey MR,
Wilson JA. Biofilms in chronic rhinosinusitis: what is new and where next?. J Laryngo Otol. 2015;129(8):744-51.

\section{Josip Culig}

University of Applied Health

Sciences, Mlinarska cesta 38, 10000,

Zagreb, Croatia

Tel: +38515495805

E-mail: jculig50@gmail.com

ISSN: 2589-5613 / O2019 The Author(s). This work is licensed under a Creative Commons Attribution 4.0 International License. The images or other third party material in this article are included in the article's Creative Commons license, unless indicated otherwise in the credit line; if the material is not included under the Creative Commons license, users will need to obtain permission from the license holder to reproduce the material. To view a copy of this license, visit http://creativecommons.org/ licenses/by/4.0/ 